\title{
GREEN PEDESTRIAN CROSSING Arte, Espaço Urbano e Cidadania
}

\author{
Susanna Almeida dos Santos ${ }^{1}$ \\ Jacqueline Barbosa ${ }^{2}$
}

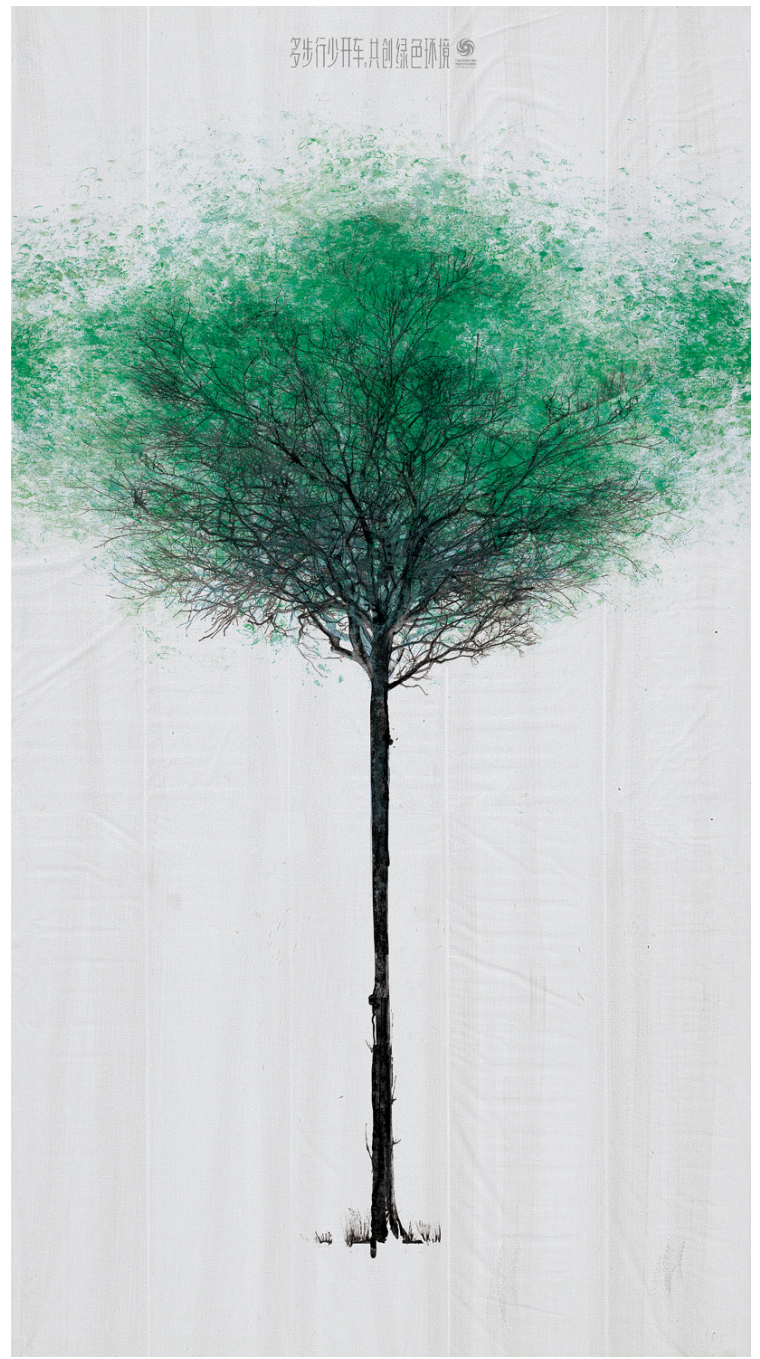

Figura 1: Green Pedestrian Cross, de Jody Xiong. Data: Setembro de 2010

Disponível em: https://www.behance.net/gallery/22053725/Green-Pedestrian-Crossing

\footnotetext{
${ }^{1}$ Graduanda em Arquitetura pela Faculdade de Arquitetura e Urbanismo da Universidade de Brasília.

${ }^{2}$ Graduanda em Arquitetura pela Faculdade de Arquitetura e Urbanismo da Universidade de Brasília.
} 
Green Pedestrian Crossing foi um projeto do artista Jody Xiong que, além de uma campanha de publicidade ao ar livre, é também uma performance, que teve o apoio da Fundação de Proteção Ambiental da China (China Environmental Protection Foundation). Difundida por meio de um vídeo oficial gravado pela agência (https://www.youtube.com/watch?v=Wq40n9BtpRk), o qual foi objeto de estudo para a interpretação, a obra é constituída de três painéis de lona, que juntos formam o desenho de uma árvore sem folhas. Estes painéis foram colocados em uma faixa de pedestre nos cruzamentos das sete principais ruas de Xangai, lugares onde há o maior conflito entre pessoas e carros na cidade.

Ao analisar a obra, percebe-se, então, uma intenção manifestada por parte do artista, ao passo que este nos mostra algo que se esconde na simplicidade de um ato, de um gesto puramente cotidiano (a travessia da faixa), nos fazendo refletir, então, sobre sua possível significação. A obra, de certa forma, pode nos revelar uma pluralidade de significados, já que há uma interpretação livre de cada um. Segundo a campanha, há um objetivo claro que é de retratar a sustentabilidade. Mas, de forma particular, cabe uma interpretação que pode ir além da questão ecológica, dos danos que o meio ambiente vem sofrendo. Pode-se, diante da análise da performance, adentrar em um campo mais sociológico, mais antropológico até, vale dizer, analisar não somente o meio, mas também, o homem e suas escolhas, o homem e sua ação com o entorno.

A obra pode ser vista em três etapas. Cada uma delas cabe uma interpretação, mas que no fim, integram-se visando um objetivo comum. Essas etapas podem ser assim descritas:

- Primeiro: a decisão de escolha do homem depois de defrontar-se com a obra;

- Segundo: a marca do homem na obra, a reflexão desta e a interpretação do ato.

- Terceiro: a ideia de vida diante de um lugar impróprio ou a ideia de uma solução diante de um caso que parece perdido.

Ao tratar da primeira etapa, vê-se que a obra instiga o homem a usufruir do seu livre arbítrio, uma vez que, interagindo com ela, ele é lançado a uma multiplicidade de escolhas, a qual caberá a ele decidir o que fazer. Neste caso, mais do que um pré-julgamento de certo ou errado, trata-se de uma intenção ou não diante da atitude tomada. Ao deparar-se com a faixa, pode-se, diante de um instinto ou de uma intenção, optar por diversas formas de travessia, sendo o importante desse ato, as consequências de suas escolhas. 
Pode-se extrapolar a ideia acima, interpretando as decisões, as escolhas tomadas, como ações do nosso dia-a-dia, em que optamos por alguma coisa diante do instinto, ou da razão, ou, ainda, por falta de opção melhor. Um fator lógico ou uma reflexão sobre nossos atos podem vir acompanhados das nossas decisões ou, darmos conta do seu efeito depois da ação feita. E, às vezes, quando o processo de reflexão se dá depois, nos questionamos se foi a melhor decisão ou, mesmo, de o porquê daquela decisão já tomada.

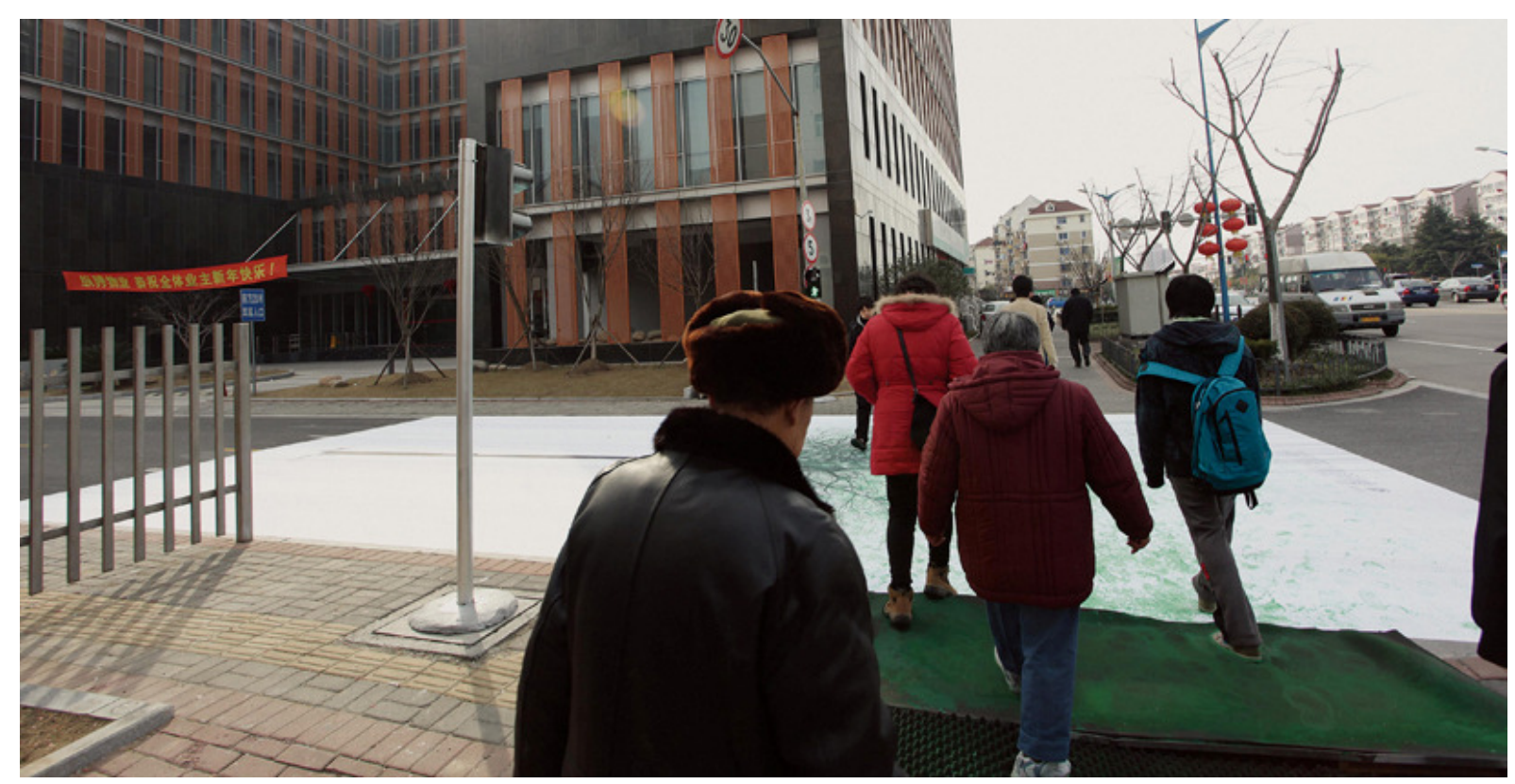

Figura 2: Green Pedestrian Cross, de Jody Xiong.

Data: Setembro de 2010

Disponível em: https://www.behance.net/gallery/22053725/Green-Pedestrian-Crossing

Ainda que haja um julgamento do certo ou errado no que fazemos, ainda que haja a moral e a ética, percebemos que nossas decisões, nossas escolhas estão acima de qualquer coisa. Ao se optar por fazer algo, independente do julgamento que isso receberá, ainda que este seja destrutivo, ele não deixará de fazê-lo, pois o motivo que o levou a fazer tal ato poderá prevalecer como o mais importante. Pode-se refletir, diante disso, a grande influência do livre arbítrio, já que sem ele nós não tomaríamos decisões por nós mesmos, mas sim, seríamos obrigados a fazê-las. O livre arbítrio, no entanto, torna-nos egoístas ao passo que passamos a tomar decisões focando o nosso bem estar e não o bem estar coletivo. Vale dizer, o motivo que nos leva a tomar tais escolhas, nossas intenções são resultados de uma ação que irá, no fim, nos beneficiar, podendo ou não, beneficiar também o coletivo. 
Cada indivíduo pode decidir fazer uso de seu livre arbítrio de maneira diferente, da mesma forma como o mesmo indivíduo, em momentos diferentes do dia, pode tomar decisões diferentes. Essa análise serve, ainda, para explicitar a complexidade das ações humanas em todos os momentos da vida e a volatilidade das atitudes de um indivíduo ou de uma sociedade. Mas, em todos os casos veem-se as consequências, que podem ser em maior ou em menor grau. Enfim, diante do exposto, cabe uma reflexão não somente de travessia de pedestres, mas também, da travessia de carros; cabe a reflexão das consequências de ambos os atos, das marcas deixadas tanto pelo homem quanto pela máquina (carro); cabe a reflexão do significado desse ato, diante do foco direto da campanha que é a sustentabilidade, a interação do homem com o meio (o significado das marcas deixadas no painel tanto pelo homem quanto pelo carro).

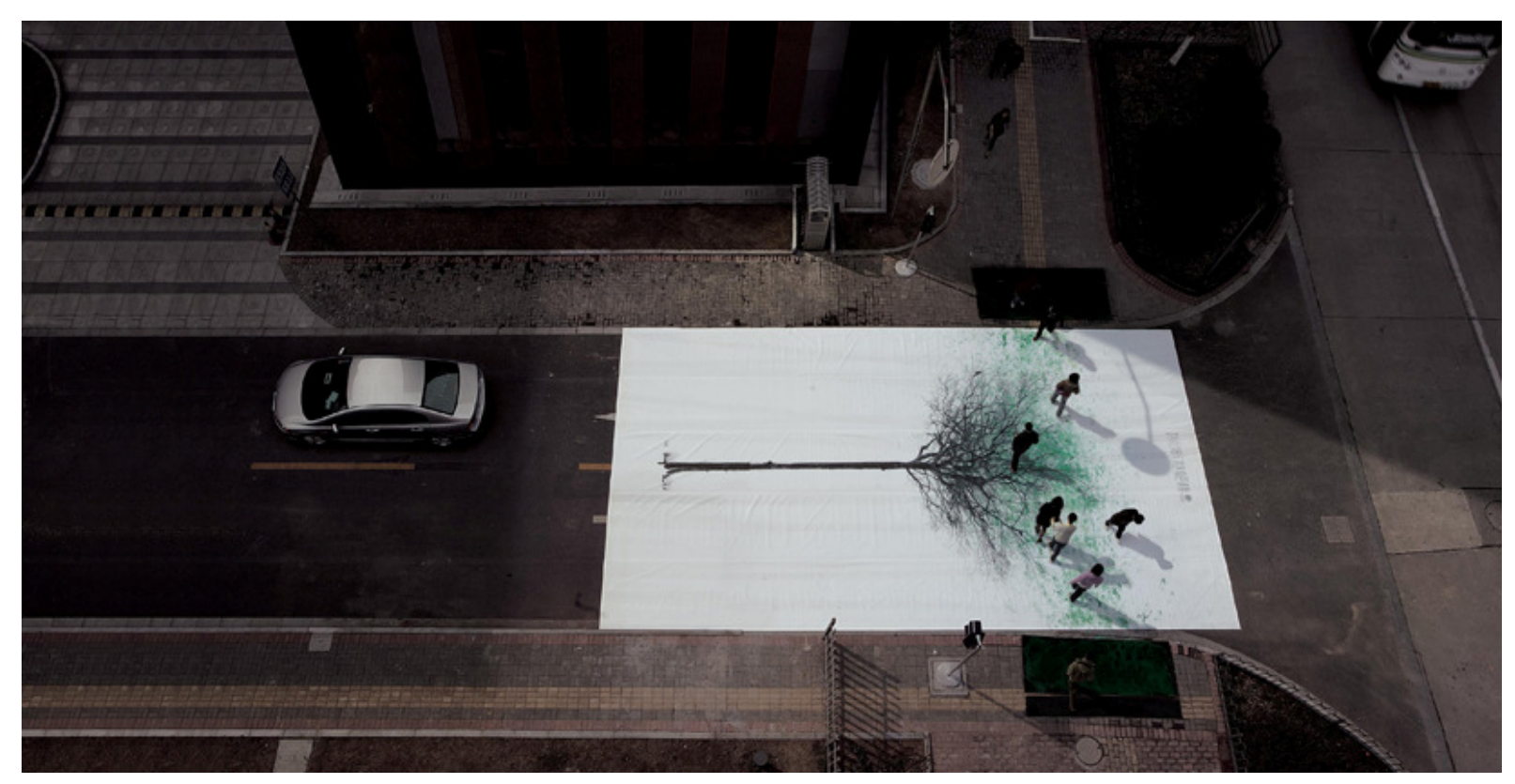

Imagem 3: Green Pedestrian Cross Jody Xiong,

Data: Setembro de 2010

Disponível em: https://www.behance.net/gallery/22053725/Green-Pedestrian-Crossing

Após toda essa análise, cabe entrar no mérito da segunda etapa da obra, cujo objetivo maior é a significação dos atos. É relevante, pois, explicitar que a significação dos atos podem tomar sentidos diferentes tanto ao retratar a obra no seu processo executivo quanto ao retratála na sua exposição na faixada do museu, Shangai Zheng Art Museum e, que ainda nessa etapa pode-se perceber, novamente, a questão do livre arbítrio. 
Ao retratar a obra no seu momento expositivo, vê-se, mais claramente, a questão do livre arbítrio, que não está retratado, agora, apenas nos agentes, nos pedestres, que permitiram o resultado final dos painéis, mas também, no artista ao decidir o local de exposição da obra. A escolha por expô-la fora do museu garante que ela não se restrinja a um grupo. Permite, pois, que ela seja difundida para todos que passem pelo local, da mesma forma como a obra não restringiu nenhum grupo em sua execução. Isto é, qualquer pessoa pode participar da performance, mostrando-nos que, independente do nível sócio cultural, raça ou opção sexual, o cidadão veja sua importância, partindo de um gesto individual, quando experimenta e participa da obra. Por fim, tendo em vista a intenção clara da campanha, a preocupação com o meio ambiente e a maior integração do homem com a natureza, e diante da análise em que as marcas dos pedestres se homogeneízam no painel, independente da etnia ou casse social, é possível fazer um paralelo com a preocupação diante da questão do preconceito, na tentativa de atenuá-lo, além de ressaltar que a ajuda à natureza pode e deve partir de qualquer um, desde que se tenha vontade para tal.

Ao tratar do processo executivo da obra e, extraindo uma reflexão além do foco direto da campanha (sustentabilidade), percebemos a importância da marca de cada um para a composição do todo artístico. Isso pode nos guiar à ideia de carimbo, já que esse se mostra, também, como uma marca em um papel. Na tentativa de explorar melhor o pensamento e, tendo em vista o conceito de carimbo, segundo o dicionário Larousse ${ }^{3}$, e, ainda, a sugestão de validação de um documento que ele autentica, é afirmado que para a obra ser validada precisa do carimbo de cada um. As pegadas carimbadas pelo homem podem fazer referência à "vida", enquanto que o carro, ao passar, além de também registrar sua marca, ele carrega consigo a marca do homem. Vale dizer, a própria criação do homem pode, também, levá-lo a morte.

\footnotetext{
${ }^{3}$ (s.m. (quimb. Ka'rimbu, marca). Instrumento de metal, madeira ou borracha com letras ou números, que serve para marcar ou datar os documentos: carimbo numerador, carimbo datador).
} 


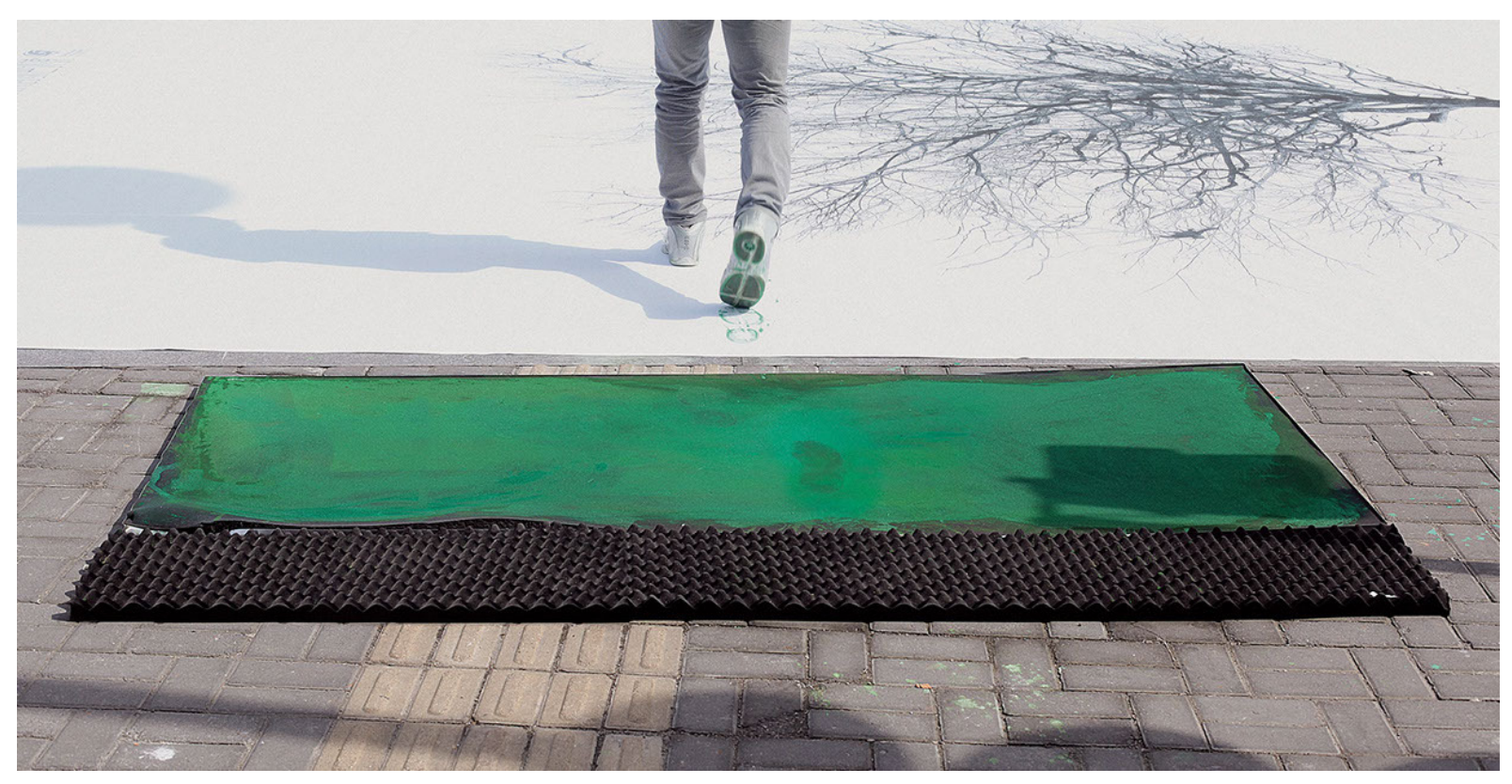

Imagem 4: Green Pedestrian Cross Jody Xiong,

Data: Setembro de 2010

Disponível em: https://www.behance.net/gallery/22053725/Green-Pedestrian-Crossing

Hoje, nos deparamos com diversas campanhas relacionadas aos acidentes de trânsito, em que por descuido do motorista, o carro pode vir a deixar marcas irreversíveis, como a deficiência física, a morte e a degradação do meio ambiente (com o aumento das emissões de carbono) que pode, indiretamente, afetar o homem. Ainda ao analisar a obra, deparamo-nos, com o cuidado que se deve ter entre motorista e pedestre, entre a fragilidade deste diante daquele, além do respeito do espaço de cada um para evitar acidentes que possam ser fatais. Diante de tudo isso, a obra reafirma a reflexão de que, às vezes, quando má usada, a tecnologia criada pelo homem pode tornar-se uma arma contra ele.

No entanto, não podemos fugir, também, de uma reflexão imediata que se depara com o foco da campanha, do impacto do homem no meio. A obra tenta, diante da poluição marcante dos carros nas cidades, gerar uma conscientização da população diante da redução de emissores poluentes, além de promover, através do jogo de palavras que está em pauta hoje que é "a pegada ecológica", um trocadilho ao passo que as pegadas do homem nos painéis vão resultar em uma árvore. Assim, a conscientização quanto ao desmatamento é de grande relevância nessa obra também. O homem, para atender seu prazer, ou às vezes por necessidade, acaba por gerar danos ao meio. No entanto, há aqueles que fazem ações, que apesar de pequenas, podem gerar consequências graves no futuro, ações essas que são feitas sem a imaginação de seus danos. O que nos parece decisivo, então, em vários níveis de reflexão, são o rastro e as pegadas que estamos deixando para trás ao continuar andando. 
Contudo, diante dessa reflexão imediata, podemos ir além ao analisarmos as pegadas do homem no painel como um desejo de mudança, de que apesar da destruição ele também pode se sensibilizar, se conscientizar e fazer sua parte para ajudar o coletivo. $\mathrm{O}$ homem, ao passar pelo painel deixa sua marca, sua contribuição perante aquela ação de ajuda ao meio. Ao visar o carro, este ao passar pelo painel deixa sua marca de forma diferente, pois ao passar por ali, ele passa por cima dos desejos coletivos, isto é, ele "esmaga", "destrói" as boas ações de um esforço comum. Isso mostra a importância de nos conscientizarmos, perante nossos atos, de como usar a tecnologia que agride o meio, independente de ser por conforto ou por necessidade, de forma a atacar menos o ambiente. Diante desse contexto, analisando a obra exposta na fachada do museu, não é possível ver as marcas do carro diante das pegadas do homem. Isso mostra que com a "pegada" (gesto) de cada um é possível amenizar os danos gerados, pois apesar de inevitáveis, somos capazes de atenuá-los.

A fim de finalizar a interpretação da obra, cabe manifestar a significação da terceira etapa. Ainda que de maneira rápida, o início do vídeo mostra uma planta nascendo do asfalto. Essa informação pode nos remeter a uma reflexão de fragilidade do homem perante a natureza. Vale dizer, enquanto a natureza precisa de pouco para sobreviver, nós não. Isso mostra que nós estamos destruindo parte da nossa sobrevivência sem repô-la de forma adequada, e a grave consequência que isso gera, já que dependemos do que a natureza nos fornece. $\mathrm{O}$ homem pode extinguir-se, mas a natureza vai se recompor e continuar existindo, enquanto que a extrema degradação dela leva-nos a um possível caos. Enfim, nós somos dependentes da natureza, mas esta não é dependente de nós, o que remete a importância de nos conscientizarmos perante nossos atos e de resguardarmos perante nosso egoísmo. O autor/artista pode estar querendo remeter ser possível existir vida ainda que em condições quase que inóspitas. É possível extrair a ideia que diante de uma situação alarmante, pode-se ter "uma luz no fim do túnel", o que nos remete a ideia de perseverança e de otimismo. Há a ideia de que se cada um fizer sua parte, ainda é possível atenuar os danos; e que para tudo, mesmo que difícil, pode haver solução.

Assim, diante das significações extraídas de cada etapa da obra, ainda que sejam amplas, pode-se delinear um objetivo em comum: a decisão e a ação do homem diante do meio e da sociedade, e suas consequências. Podemos nos questionar como uma simples decisão pode afetar a relação do homem com o mundo e com o seu arredor. Podemos nos deparar diante da ideia de que por mais que se passem os anos e que as opções ainda possam ser as mesmas, as escolhas poderão ser diferentes, segundo o que o meio impõe e visto o uso 
do livre arbítrio de cada um. As consequências geradas na sociedade são resultados das escolhas de cada um, ainda que estas sejam dadas de forma intencional, ou puramente intuitiva, ou segundo o que convém (ato do egoísmo).

Tem-se, pois, clara a importância da ação de cada um para tornar o meio melhor ou pior. Depende da nossa conscientização para reverter nossas más ações em qualidade de vida não somente para hoje como para o futuro. Devemos nos questionar até que ponto nosso egoísmo pode sobressair contra o bem coletivo. Enfim, ainda que por vezes ignorantes perante as consequências das nossas pegadas, devemos o mínimo para aquela que, ainda que imperceptível por muitos, nos serve e nos mantém vivos: a natureza. 